\title{
The integration of lean, green and best practice business principles
}

\begin{abstract}
Authors:
Annelize Wiese ${ }^{1}$

Rose Luke ${ }^{1}$

Gert J. Heyns ${ }^{1}$

Noleen M. Pisa ${ }^{1}$

Affiliations:

${ }^{1}$ Department of Transport

and Supply Chain

Management, University of

Johannesburg, South Africa

Correspondence to:

Rose Luke

\section{Email:}

rluke@uj.ac.za

\section{Postal address:}

PO Box 524, Auckland Park

2006, South Africa

Dates:

Received: 21 May 2015

Accepted: 04 Aug. 2015

Published: 07 Oct. 2015

How to cite this article:

Wiese, A., Luke, R., Heyns,

G.J. \& Pisa, N.M., 2015, 'The

integration of lean, green

and best practice business

principles', Journal of

Transport and Supply Chain

Management 9(1), Art. \#192,

10 pages. http://dx.doi.

org/10.4102/jtscm.v9i1.192

\section{Copyright:}

(C) 2015. The Authors.

Licensee: AOSIS

OpenJournals. This work is

licensed under the Creative

Commons Attribution

License.
\end{abstract}

\section{Read online:}

Background: Whilst there are separate streams of established research on lean, green and best practice initiatives, the intersection of these three strategic principles has not been addressed extensively in the past.

Objectives: In this study a framework to integrate lean, green and best practice principles into an integrated business model was developed as a strategy for businesses to develop sustainable competitive advantages.

Method: A descriptive case study was conducted on Toyota South Africa Motors (TSAM) to understand whether a clear link between the company's environmental approach, lean principles and established best practice culture could be determined. In addition, the case study tested the view that the implementation of these three principles concurrently resulted in improved business results.

Results: The main findings of the study revealed that TSAM's commitment to lean, green and best practice business principles contributed and was directly linked to its business success in terms of sales and market position.

Conclusion: It is recommended that businesses implement an integrated lean, green and best practice business model as a strategy to reduce costs and sustainably enhance profitably and competitiveness.

\section{Introduction}

The participation in and management of modern supply chains is characterised by various complexities, including: intense competition, rising demand for cleaner products, environmental sustainability issues and pressures to reduce and manage waste (Ponis \& Koronis 2012; Ponis \& Spanos 2009). Consumers now insist on 'cleaner' products that minimise waste, environmental damage and pollution (Vermaak 2008). Maintaining a competitive advantage in modern supply chains requires a 'vision that includes environmental sustainability' (Wills 2009). Resultantly, successful businesses are combining 'lean' and 'green' strategies to identify and eliminate waste generated as part of their daily operational processes (Wills 2009). By integrating lean and green thinking, significant cost savings across supply chain functions may be realised, as the unnecessary usage of resources or processes that generate waste (which may be harmful to the environment and otherwise) are identified, reduced or eliminated (Beske \& Seuring 2014; Schaltegger \& Burritt 2014; Stindt \& Sahamie 2014).

In addition, businesses are faced with the challenge of identifying cost saving opportunities within an organisation, or network of organisations, that will reveal best practice solutions (Wills 2009). Best practices cut out unnecessary or wasteful activity throughout all organisational levels and are directly linked to the objectives and benefits of lean and green thinking (Verrier et al. 2014). Whilst there are separate streams of established research on lean, green and best practice initiatives, the intersection of these three strategic principles has not been addressed extensively in the past. Schmidt and Lyle (2010) touched on the integration of lean principles with various other business practices in order to achieve competitive advantage, although lean, green and best practice principles were not the focus point of the research. This reveals a critical oversight as organisations may be missing synergies available through improved concurrent implementation of these three principles.

Whereas research coverage of the combination of lean and green practices have received relevant academic research coverage (Bergmiller \& McCright 2009; Cabral, Grilo \& Cruz-Machado 2012; Dües, Tan \& Lim 2013; Galeazzo, Furlan \& Vinelli 2014; Martínez-Jurado \& Moyano-Fuentes 2014), the combination of lean, green and best practices has not been widely researched. Against this backdrop, the main aim of this article is to establish a framework to integrate lean, green and 
best practice principles into an integrated business model that businesses can implement to become more competitive. A descriptive case study was conducted on Toyota South African Motors (TSAM) to illustrate the benefits that may arise when these three principles are successfully implemented and incorporated into a supply chain business strategy concurrently. The rest of this article is structured as follows: Section 2 provides a theoretic overview on the lean, green and best practice business principles, particularly highlighting the definitions, characteristics and associated benefits of implementing these business principles. Section 3 presents the integrated lean, green, best practice business model, whilst Section 4 describes the research method. The results of the study are presented in Section 5 and Section 6 concludes the article.

\section{Literature review}

Scholars, business consultants and senior managers in practice are increasingly focusing on the concept of supply chain management and improvement of internal processes (Beske \& Seuring 2014; Schaltegger \& Burritt 2014; Stindt \& Sahamie 2014; Verrier et al. 2014). Many organisations have begun to recognise that effective supply chain management is the key to building a sustainable competitive edge for their products and services (Jones 1998). Successful organisations recognise that effective supply chain management reduces costs by eliminating non-value adding activities and creates a set of new market capabilities that are difficult to replicate (Groznik \& Maslaric 2009). These market capabilities can be developed through the implementation of various business practices, which may include lean, green and best practice principles.

\section{Lean principles}

'Lean', also known as 'lean production', is defined as efficiency with no wastage and focuses on implementing value-adding processes without interruption (BMGI Corporation 2009; Womack \& Jones 2005). Lean thinking focuses on reducing or eliminating all non-value adding activities within the supply chain, thereby reducing costs at various points throughout the supply chain process (Dües et al. 2013). Lean principles deliver superior performance delivering goods to the end customer quickly, with the minimum amount of waste or inefficiency and creating the most possible value for stakeholders. According to Olesen et al. (2015), lean thinking is an enabler for any company to become more efficient in production speed and flow and is all about achieving operational excellence and sustainability.

The essence of a lean approach requires a commitment to eliminate waste, simplify procedures and maximise value in a supply chain. In order to enhance value, organisations need to understand which activities truly create value for their shareholders. Value-adding activities transform materials and information into something useful and valuable, which the customer requires in a specific form at a specific point in time. Maximising value within an organisation will provide the right incentives to all employees to increase productivity and overall efficiency of an organisation (Business Blog 2012; Castillo, Alarcón \& González 2015). This complements the objectives of effective supply chain management, which includes delivery of quality products and services on time, every time and at the right cost, whilst being flexible and responsive to customer demands (Dües et al. 2013; Kotelnikov 2001).

\section{Green principles}

In recent times more focus and effort is being placed on the business's carbon footprint and the environmental impact of its activities (Franchetti et al. 2009). A green supply chain is the extension of the traditional supply chain to include the total direct or indirect environmental effects of goods, processes and procedures within a supply chain (Lamming \& Hampson 1996; Sobral, Jabbour \& Jabbour 2013). Green principles are based on the recognition that the environmental impact of a business includes the environmental effects of all products and activities, from the withdrawal of raw materials, to the use of materials in production, the distribution of the materials, the consumption and the final disposal of those materials (Lamming \& Hampson 1996; Zokaei et al. 2013). Green supply chain management (GSCM) focuses on eliminating environmental pollution and waste in terms of energy, emissions and chemical excess throughout all phases of a product's life and throughout the entire supply chain (Wu, Cheng \& Huang 2010).

GSCM also encompasses green procurement, green manufacturing, green distribution and green reverse logistics (Ninlawan et al. 2010). Green procurement involves the purchasing of environmentally friendly products or services, the selection of contractors that meet agreed environmental standards and the setting of environmental requirements in a contract (Srinivas 2011). It also takes into consideration environmental protection, energy conservation, resource conservation and ease of recycling (Hitachi Consulting Corporation 2009). Green manufacturing promotes the development of products that are energy efficient, recyclable, easy to dispose of and produce less overall waste during the manufacturing process. It supports a renewable way to produce products or services that will not harm the environment (Dornfeld 2009). D'Amato, Henderson and Florence (2009) found that manufacturing companies realise that to increase global competitiveness, implementation of sustainable and green processes for environmental and social purposes as well as compliance with international standards has become a necessity.

Environmental considerations are also important when moving raw materials and manufactured items through the supply chain. Green distribution includes activities such as environmental impact analysis of transport modes, transport selection, setting up contracts as well as making decisions regarding trade-offs between cost, quality, technology, service and environmental impacts (Mallett 2010). Rodrigue, Slack and Comtois (2012) expand this definition and state that green distribution refers to supply chain distribution strategies that reduce the energy footprint of transport 
activities and processes. Green distribution can be achieved by implementing distribution rules, disciplined load planning operations, visibility into idle waste and alternative transport mode selection programs. Mallett (2010) states that organisations that incorporate environmentally conscious distribution choices, both to customers and upstream to their supplier base, will not only reduce the costs of bringing products to market, but also differentiate themselves to customers, strategic partners and investors.

Ho et al. (2009) and Singh, Bharati and Kumar (2013) define reverse logistics as the process of retrieving the product from the end consumer for the purpose of recapturing value or proper disposal. It includes the process of:

planning, implementing and monitoring the efficient, costeffective flow of raw materials, in-process inventory, finished goods and related information from the point of consumption, back through the supply chain and possibly to the point of origin. (De Brito \& Dekker 2003:489-498; Singh et al. 2013)

\section{Best practices}

The Hackett Group (2006) defined best practices as proven, repeatable, documented techniques that deliver measurable performance improvements. Many best practices seem to strive for consistency, simplification of procedures, zero redundancies or wasteful activities, technology leveraging and standardisation (Evans 2010). This strategy ensures greater efficiency, elimination of mistakes and wasteful activities, sustainable business processes and an increased level of value to the customer, which ultimately leads to business growth, competitive advantage and increased profitability (Sternbeck \& Kuhn 2014).

A study conducted by the Hackett Group (2006) found that by successfully implementing best practices, businesses can significantly reduce costs, be more effective, deliver higher quality services and reduce risk. Best practices are associated with business process re-engineering initiatives where organisations benchmark processes and practices (Anderson et al. 2005; Wagner, Scott \& Galliers 2006). These practices are recognised as being best by function or within an industry and can be adopted by other organisations looking to improve their supply chains (Engel 2011). IBM (2009) defines best practice as a technique or methodology that, through experience and research, has proven to lead reliably to a desired result. As best practice methodologies become available for businesses they shift from being a source of competitive advantage to standard prerequisites for business efficiency (Porter 2001; Wagner et al. 2006).

Decision-makers and executives within a supply chain look to best practices to assist them in speeding up their progress toward performance improvements (Hackett Group 2006). Once best practice business models are successfully applied, it is expected that companies will gain significant competitive advantage which will lead to growth and increased profits (Engel 2011; Hammer 1999; Wagner et al. 2006). The main dimensions to enabling best practices include visible leadership, identification and understanding of inhibitors to managing best practices and the appreciation of the degree to which improvement would be dependent on resources (Jarrar \& Zairi 2010).

\section{Building an integrated lean, green, best practice business model}

Following an in-depth literature review a framework was developed to amalgamate lean, green and best practice principles into an integrated business model. The literature review revealed that the lean and green principles are similar to the principles underlying the formulation of best practices and that together these three principles result in complementary improved business results. Businesses can improve results by concurrently implementing the lean, green best practice principles in an integrated model. Figure 1 illustrates this. A case study was conducted on TSAM to illustrate the benefits that may arise when the lean, green and best practice principles are successfully implemented and incorporated into a supply chain business strategy. This is the first study to develop and test a business model integrating the lean, green and best practice principles.

Studies have shown that the goals of implementing lean and green principles are similar to those of best practices, that is, to reduce respective waste (EPA 2003a). Bergmiller and McCright (2009) suggest that a model that integrates lean and green implementations into one comprehensive practice that focuses on reduction of all waste can be the most effective and efficient path to long-term organisational sustainability and can ultimately lead to overall competiveness. By definition, lean and green thinking focuses on improved business results in terms of cost, market position, reputation and product design. Consequently, lean and green principles, directly integrated into a basic organisational business model, will be more effective than other methods at delivering a specific outcome if the key strategy and objective of the model is to reduce waste and maximise profit. This qualifies the incorporation of lean and green principles into the existing business model as part of the strategy to become a best practice model (Bergmiller \& McCright 2009).

Implementing lean principles in a supply chain should provide a clear objective of achieving efficiency whilst preventing or eliminating waste (D. Meyer 2009). A green focus in supply chain management requires a review of environmental considerations and consideration of extended stewardship opportunities in all stages of a product's existence (EPA 2003b). Lean and green practices focus on enhancing value for the customer by collaborating with suppliers and customers, analysing existing operations and identifying opportunities to reduce waste by operating more efficiently. Rothenberg, Pill and Maxwell (2001) confirm that there are strong correlations between lean practices and environmental performance.

The basic concept of lean refers to the elimination of waste in every aspect of a supply chain while adding value 


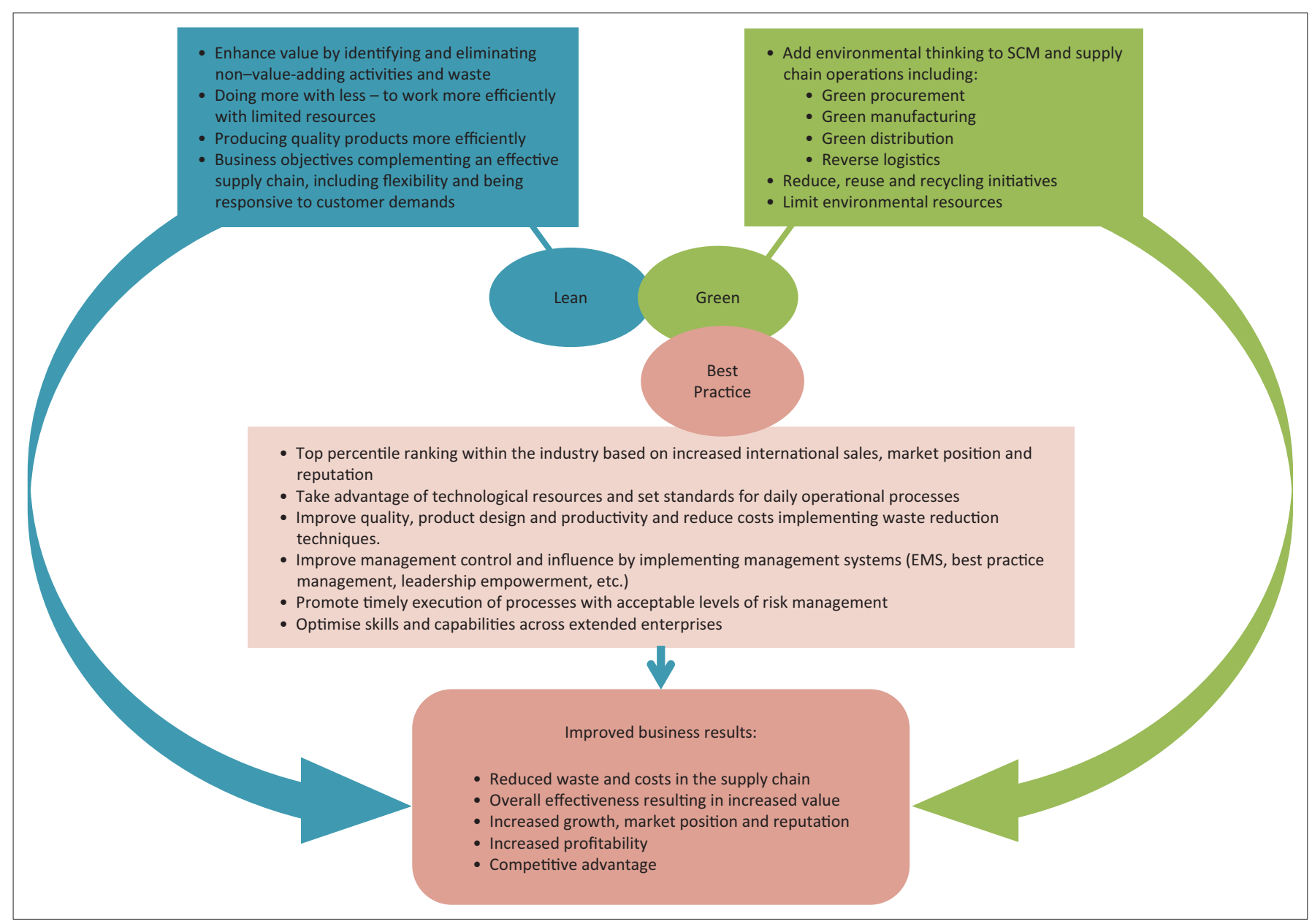

FIGURE 1: Key attributes of an integrated lean, green and best practice concepts.

for customers' (BMGI Corporation 2009). Even without specifically targeting environmental outcomes, lean efforts have demonstrated substantial environmental benefits. This includes pollution prevention, reuse and recycling opportunities and general waste reduction (D. Meyer 2009). K.E. Meyer (2009) explains that 'because environmental wastes and pollution are not the primary focal points of lean implementations, the gains may not be maximised in the normal course of a lean initiative'.

\section{Research method}

The study followed a qualitative approach. Three sources of evidence, namely semi-structured interviews, testimonials from experts and document reviews, provided the basis of this case study. A single case design was used to analyse TSAM. The case of TSAM implementing lean, green and best practice has resulted in the organisation being an industry leader. The interviews and testimonials obtained from interviewing 11 senior managers from TSAM, Barloworld and the automotive industry body NAAMSA provided access to overarching views from the departments and stakeholders involved in the implementation of lean, green and best practices in TSAM (L. De Waal, pers. comm., March 2011; L. De Wet, pers. comm., October 2011; H. FitzSimons, pers. comm., July 2013; K. Knight, pers. comm., May 2011; J. Kruger, pers. comm., August 2011; S. MacMillan, pers. comm., February
2012; R. Muller, pers. comm., May 2011; R. Stutterheim, pers. comm., February 2011; H. Swanepoel, pers. comm., February 2012; C. Van Rooyen, pers. comm., February 2013). For the purpose of this study the unit of analysis was TSAM, in particular TSAM's Service Parts Logistics business as well as the Environmental Management Systems (EMS) division. Individuals from these two divisions in TSAM were included in this case study to inform understanding of the functioning and added value of implementing lean, green and best practice principles in TSAM (M. Bowers, pers. comm., April 2013; L. De Waal, pers. comm., March 2011; H. FitzSimons, pers. comm., August 2012; J. Kruger, pers. comm., August 2011; C. Van Rooyen, pers. comm., February 2013).

The 'guided keyword search' technique was used to apply focus in gathering the information. Figure 2 illustrates the schematic representation of the research design framework for this project.

The guided keyword search technique was employed to gather data from the document review. This proved to be helpful in determining links or relationships between specific terms. Keywords can also be used as a substitute for literature title or author searches when the researcher has incomplete title or author information. The guided keyword search option is used to combine search elements or terms. This method was used to search and establish the possible 


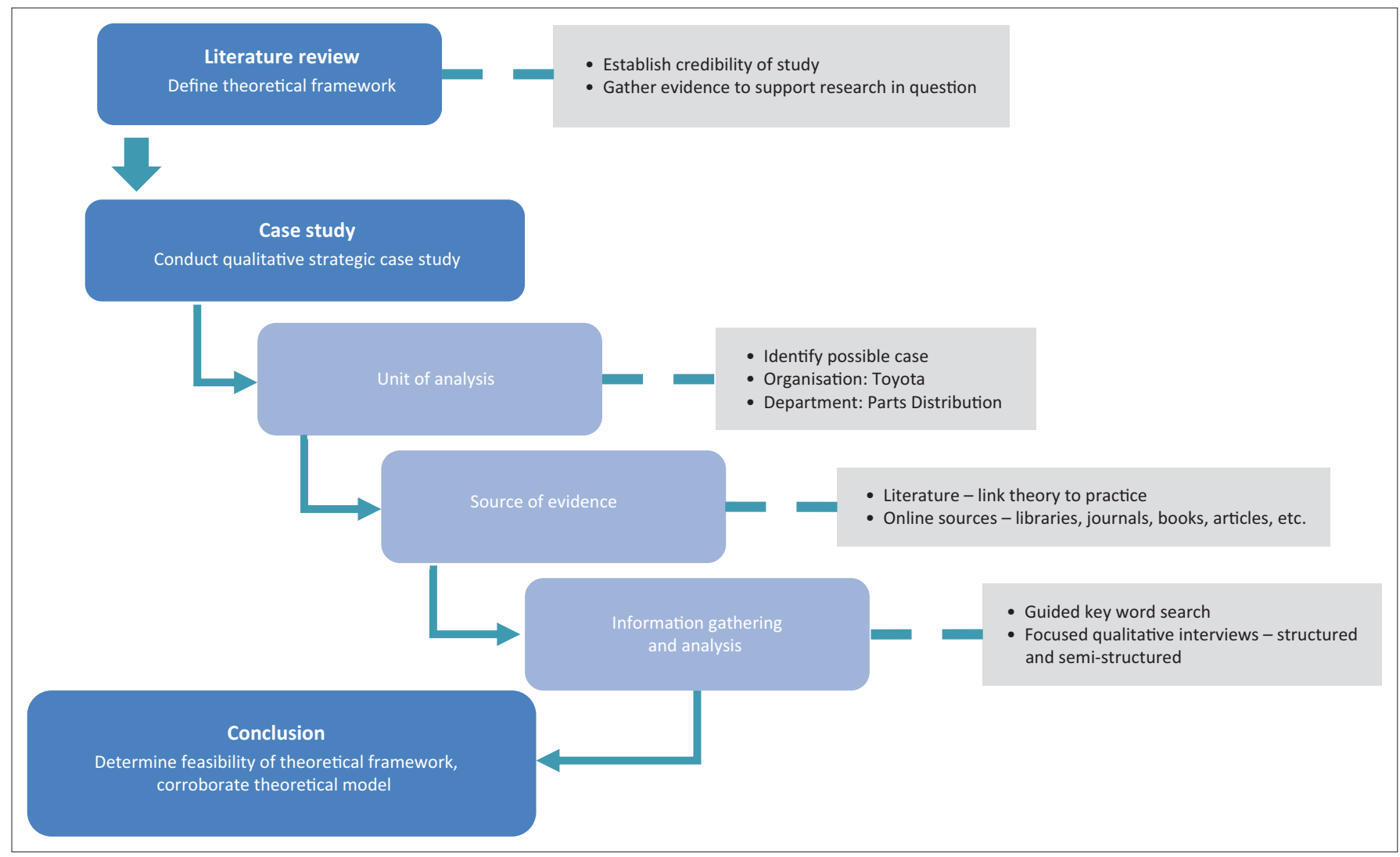

FIGURE 2: Research approach and design.

link between the three principle research elements of this study, that is, the terms lean, green and best practice.

The literature review and document review provided input into the structuring of the case study and the interviewing process. The theory of lean and green best practices in a supply chain context was analysed and evaluated to achieve a thorough understanding of these concepts and its objectives. The results of this primary research guided the questions asked in the interviews held with various industry specialists. Industry specialists were chosen for the interviews based on their experience and knowledge in the respective fields. Their current and past positions held at leading supply chain organisations were fundamental to their being selected for the interviewing process.

For the key informant interviews the questions were structured around how the South African business lives up to the global perception and reputation of Toyota and how 'the Toyota Way' is being incorporated into local business decisions as well as the company's commitment to environmental matters. The document review provided an understanding of the definition, characteristics and associated benefits of the lean, green and best practices principles and substantiated actual performance data. Major points and themes providing evidence of TSAM's accomplishments from implementing lean, green and best practice principles were recorded.

Once relevant data from the documents were identified, they were compiled to form a list of projects, products and activities representing TSAM's accomplishments. Finally, testimonials were provided by experts in TSAM and Barloworld Logistics to further elucidate the benefits derived from the implementation of lean, green and best practice principles. The overall study questions examined how TSAM implemented lean, green and best practice and identified the associated benefits.

\section{Findings}

The global automotive industry has always set standards in automated production processes (Siemens 2008). Structural changes in the automotive production over the past decade, combined with innovative technologies, have resulted in excellent production processes with reduced costs, increased flexibility and increased agility, assuring availability. The Toyota Motor Corporation (TMC) forms part of the Toyota Group, the largest international corporation in the world. According to a survey conducted by OICA (2013), TMC ranked amongst the world's leading global corporations on vehicle sales, realising global sales of more than $\$ 228.5$ billion. TMC's performance was a direct result of operational excellence and was based on tools, quality improvement techniques and principles made famous by Toyota in the manufacturing and automotive industries. According to Liker (2004), 'Toyota has turned operational excellence into a strategic weapon', but he also states that a set of tools alone cannot transform a business. 'The Toyota Way' was written by Liker after observing and studying the company, its principles, its strategies and culture for 20 years. It is 
a comprehensive set of practices that underlie Toyota's managerial approach and production system (Toyota Blog Online 2012). 'The Toyota Way' consists of 14 principles grouped into four pillars or categories.

In recent years, TSAM, together with Barloworld Logistics, has worked on various projects to make processes in the TSAM supply chain more efficient and environmentally sustainable (De Waal, pers. comm., March 2011). The case study focuses on the distribution part of the TSAM supply chain where its environmental plan is analysed to determine whether the plan can be linked to the already existing lean strategy and the business's best practice culture.

The decision to conduct a case study on the TSAM business was motivated by the organisation's reputation in lean and best practice performance as well as its market position in the supply chain and automotive industries. The integration of green into business strategies is not as apparent in Toyota's success as the lean and best practice principles have proven to be. The case study provides analysis of this element to determine the level of integration of these three principles and the contribution thereof to TSAM's success.

The case study revealed perceptions, rules and key performance in TSAM that are not always documented in publicly available information. In-depth analysis regarding business principles and culture was required to support the objective of this project. The information collected by the interviews proved invaluable in identifying the possible correlation between lean, green and best practice business principles and improved business performance in TSAM.

There is a strong drive in TSAM to enhance value for stakeholders by directing business activities through cost reduction initiatives, eliminating waste and thereby increasing efficiency of business processes. Various strategies were implemented to accomplish set targets related to the reduction of the identified wastes and to improve business performance and TSAM's competitive advantage. The following identified, measureable tactics were implemented as part of their commitment to lean, green and best practice philosophies.

\section{Increased use of returnable packaging}

TSAM initiated a strong drive to reduce packaging materials, in particular plastic and to increase the use of returnable packaging. Plastics used for packaging material are generally more expensive to produce and heavier to ship than cardboard and paper-based materials (Westlake 2012). As a result TSAM substituted plastic with cardboard, paper and wood for the distribution of service parts, locally or internationally. This benefit of adding flexibility by using cardboard instead of plastic or other heavy metal material for shipping supports both the lean and green principles, thereby complementing effective supply chain management (see Figure 1).

TSAM's targets for packaging consumption dropped significantly since 2010 as the active drive to reduce this waste commenced. A 1\% reduction target was set for the financial year of 2011, a 5\% target was set for 2012 and a further 5\% reduction for 2013 (TSAM 2012). Although the target for 2011 was comfortably met, the targets for 2012 and 2013 were not quite achieved owing to the additional packaging requirements during the establishment of the new distribution facility in Boksburg, Gauteng.

\section{Consolidation of orders and improved fill rates}

TSAM's Parts Distribution business grew by R1.5 billion in the period 2007-2013. As part of Toyota's global environmental programme to reduce emissions and transport waste across the supply chain, all parts and accessories activities were consolidated at a single facility and managed centrally to optimise operations and avoid unnecessary waste generation in the supply chain. This resulted in a decision to develop a new warehouse facility in Boksburg, Gauteng (De Waal, pers. comm., March 2011). This project supports the effective problem-solving pillar - through decision-making by consensus - by creating a full understanding of the situation and the challenges faced from the steep business growth.

Packaging initiatives implemented at the new distribution centre were, firstly, the reuse of cardboard boxes, mainly used for bulk storage, high volume picking activities and exports. The reuse of cardboard packaging resulted in significant and direct cost savings (De Waal, pers. comm., March 2011). Secondly, for local shipments returnable containers were used where feasible. This supports the lean element of TSAM's business model. The 'doing more with less' scenario as well as an increase in efficiency applies. By dispatching returnable containers and managing the process of collecting the containers as part of daily delivery activities without introducing additional transport lags, TSAM was able to increase efficiency. The returned containers are readily available for dispatch as soon as they return from the various collection points. Thirdly, packaging consumption was tracked and vehicle utilisation monitored and adjusted, where required, to increase efficiency. This element also contributed to increased importance of reverse logistics as well as greening in the organisation (see section 3 ).

Dispatch and the use of returnable packaging consumption were not always monitored and reported but since April 2012, a significant increase in returnable containers dispatched was recorded (attribute of lean). Figure 3 illustrates the increase in returnable container usage between April 2012 and March 2013. This trend was expected to continue into the 2013 and 2014 financial years.

\section{Improve Carbon dioxide measurement across all transport modes}

Continual measurement and reviews are done to set timeous targets and implement action plans to achieve objectives regarding Carbon dioxide $\left(\mathrm{CO}_{2}\right)$ performance. TSAM has a strong drive to promote the successful measurement of performance in order to manage results. Sales volumes of 


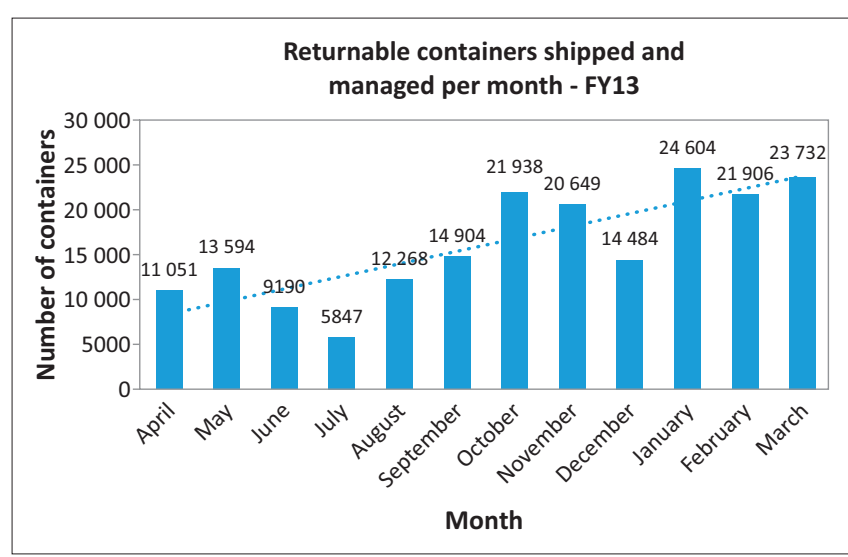

Source: Toyota South Africa Motors (TSAM), 2013, Toyota South African Motors sustainability report 2013, TSAM, Pretoria

FIGURE 3: Toyota South Africa Motors' returnable container usage.

TSAM service parts increased significantly between 2011 and 2013, resulting in the increase in average emissions per vehicle or part shipped. This increase in $\mathrm{CO}_{2}$ emissions was perceived to be a result of business growth. As a result, the new parts distribution facility was built in Boksburg to increase efficiency and reduce environmental waste.

Waste management procedures were put in place with specific focus on $\mathrm{CO}_{2}$ reduction. The following green principles in the form of waste management were initiated at the Boksburg plant from the official launch of the facility in late 2012. Physical waste in the facility was separated and taken to a waste management area where recyclables were further sorted for reuse and recycling purposes. Secondly, the facility's carbon footprint was calculated and reviewed on an ongoing basis. The objective was to show continuous reduction in $\mathrm{CO}_{2}$ generated per $\mathrm{km}$ or unit shipped. Thirdly, packaging reduction programmes were implemented both to reduce environmental impacts and for direct cost saving purposes. The facility received a positive ISO 14001 environmental audit report after a very short period of being in operation. ISO 14001 is an environmental management standard that specifies a set of environmental management requirements for environmental management systems. ISO 14001 requires an organisation to manage and control its impact on the environment (ISO Online 2011; Whitelaw 2004).

\section{Introduce three suppliers to execute routine round-trip deliveries}

Routing round-trip deliveries facilitates both collection and distribution and results in a reduction in planning requirements and transport costs. A pilot project was initiated to begin routine round-trip deliveries in the KwaZuluNatal area. The aim was to measure the yield performance of this initiative across the country. The expected outcome was a reduction in labour and transportation costs due to the successful execution of daily return loads and increased vehicle fill rates and optimisation. The principle of process enhancement in 'the Toyota Way' is supported by this initiative as it represents the levelling out of workloads directly aligned to the main attributes of lean (see Figure 1).

\section{Reduce unnecessary idling of courier vehicles in the yard}

To ensure that fuel use during idling is accurately measured, TSAM introduced all couriers to fuel performance measurement in terms of $\mathrm{CO}_{2}$ emissions. Fuel performance in terms of $\mathrm{CO}_{2}$ emissions is measured by monitoring and recording fuel efficiency per vehicle per day. Minimising fuel consumption reduces $\mathrm{CO}_{2}$ emissions naturally. Consequently, the successful implementation of this task would automatically generate a greener result. The effective management of supply chain partner relationships plays an integral role in achieving this objective. Resultantly, workshops and programmes were be implemented to educate suppliers on the concept of green and environmental performance measurement and the management thereof. The above initiatives improved environmental performance by continuously measuring and reviewing performance, conducting follow-ups and ensuring that corrective action plans are in place when setting targets for the following years.

\section{Energy efficiency}

Electricity, methane and liquefied petroleum gas are the main energy sources used by TSAM. Lower production volumes as a result of the economic downturn caused the electricity consumption to drop from 132801 tonnes of $\mathrm{CO}_{2}$ in 2008 to 112457 tonnes in 2009. Furthermore, total energy usage dropped by 26210 tonnes $\mathrm{CO}_{2}$ in 2008 mainly owing to the implementation of initiatives to reduce energy consumption in all production facilities. These initiatives included tasking staff to switch off lights, fans and other electrical appliances during production downtime in each operational area. In addition, power equalisers were installed in the welding and exhaust plants. Equalisers are used to stabilise the voltage supplied to welding machines. This reduces the energy consumed during operation and improves the quality of welds. The decision to purchase and employ these stabilisers was based on a long term-philosophy. The investment was quite significant at first, but proved to be financially beneficial due to the reduction in energy costs over the long term. Ventilation fans and lights were automated to switch off during production downtime. These initiatives led to a reduction in electricity costs and other costs associated with energy sources and can be linked directly to improved business results: reduction in waste and costs in the supply chain (see Figure 1).

\section{Compliance of suppliers to green purchasing guidelines}

TSAM issues the 'Green Purchasing Guideline' to all suppliers once a year to ensure that all suppliers or potential suppliers are aware of their requirement to comply with applicable laws, regulations and social norms. (TSAM 2012:n.p.)

TSAM requires that suppliers are ISO 14001 compliant. Compliance to this standard is important as it assists in improving environmental performance across the supply chain. TSAM strives to have a 100\% supplier certification, but only achieved $87 \%$ in 2010 . There is currently a strong drive 
to improve this across the TSAM business. All suppliers are expected to sign declarations confirming that their products are free of 'substances of concern'.

\section{Improve quality control and status reporting on 'substances of concern' (lean, green and best practice)}

Approximately 100000 chemical substances are being manufactured and sold throughout the world (TSAM 2012). Many of these substances impact negatively on the environment and affect human health. These are defined as 'substances of concern'. At TSAM, all chemical products used in production are screened for banned substances and prohibited from production activities. TSAM's 2011/2012 Logistics Environmental Business Plan requires suppliers to maintain a $100 \%$ conformance to their 'substances of concern' mandate. This relates strongly to environmental goals, as substances which may harm to the environment will have to be properly managed to minimise the effects on the immediate environment. This objective supports the principle of enhancing and managing supplier relationships by implementing a compliance programme to TSAM's set standards in terms of environmental performance and quality of parts (attributes of best practices).

Random tests are performed on Toyota parts, components and packaging material at each facility to ensure compliance with TSAM's 'substances of concern' mandate. TSAM will use the opportunity to perform quality checks to ensure that supplier products meet set quality standards and environmental waste is minimised. This action relates to best practices, that is, setting standards for daily operational processes, ensuring quality and thereby cutting costs by reducing waste. 'Substances of concern' declarations are to be completed by all new suppliers to ensure that new parts are processed via the portal. An effective management system will be required to accomplish this task, not only for managing suppliers, but also for managing environmental performance (EMS) and risk within the operation. Risk management and improving management control and influence by implementing management systems assists in defining best practice.

Commencement with status reporting on 'substances of concern' and growing the list of substances as and where relevant is the next action to be implemented to achieve this objective. This action is a direct requirement from Toyota's headquarters in Japan (De Waal, pers. comm., March 2011). Performance measurement and reporting represent the implementation of management systems, the optimisation of skills within the company as well as identifying and managing risks to ensure that operations are being executed within acceptable levels of risk management.

\section{Conclusion}

Integrated lean and green business models have been proven to result in the realisation of cost saving across supply chain activities. In addition to implementing lean and green business strategies to recognise savings, the challenge is to develop best practice solutions that enhance and sustain the business's competitiveness within an industry. Whilst there are separate streams of established research on lean, green and best practice initiatives, the intersection of these three strategic principles has not been addressed extensively in the past. Following an in-depth literature review, a framework was developed to integrate lean, green and best practice principles into an integrated business model. The literature review revealed that these three principles are complementary and result in improved business results. A descriptive case study was conducted on TSAM to understand whether a clear link between the company's environmental approach, lean principles and established best practice culture could be determined. In addition, the case study tested the view that the implementation of these three principles concurrently resulted in improved business results, thereby supporting our view that an integrated business model results in improved business results.

The main findings of the study were that TSAM implements strategies from 'the Toyota Way' into its decisions and is committed to environmental matters. In addition a clear link between the company's environmental approach, lean principles and established best practice culture was established and was substantiated, using actual performance data. TSAM has an established presence in the automotive industry owing to the implementation of lean, green and best practice principles. The following initiatives were implemented and measured over a period of time to determine the impact of these activities on TSAM's business and environmental performance as well as their contribution to achieving TSAM's goals. Firstly, orders were consolidated and fill rates were improved to reduce handling, transportation and various other costs (lean and green). The use of returnable packaging (green) was increased to minimise waste and reduce costs. In addition, 'the reduce, reuse and recycling' initiatives were initiated and promoted (lean, green and best practice). Another initiative to improve the measurement of performance was implemented in order to improve performance management. This included the managing supplier relationships by educating partners on effects and measurement of $\mathrm{CO}_{2}$ performance (lean, green and best practice).

The routine deliveries initiative was introduced to facilitate collection and distribution reducing transport costs and planning requirements (lean and green). Furthermore, the green initiative to stop redundant idling of courier vehicles has a direct impact on the $\mathrm{CO}_{2}$ emissions per vehicle per trip. This was measured by monitoring and recording fuel efficiency per vehicle per day. The final initiative involved switching off unnecessary lights, fans and other electrical appliances (lean and green) and installing power equalisers at plants as part of EMS (green and best practice). Reductions in electricity consumption were observed from data recorded to measure performance on this initiative. 
Overall, these initiatives contributed to improved business results for TSAM. The case study also revealed that vehicle sales for TSAM have increased year after year and that they remain the leaders in the South African automotive industry. This indicates that TSAM's commitment to lean, green and best practice business principles contributes and is directly linked to its business success in terms of sales and market position. This study provides evidence that there is a strong correlation between lean and green thinking as both principles focus on reducing waste, decreasing costs and enhancing value for all stakeholders and partners within a supply chain. The benefits of implementing an integrated lean, green and best practice business model have become clear when examining TSAM's environmental plan and establishing the relationship of the environmental strategy with the concept of lean and best practice principles. It is recommended that businesses implement an integrated lean, green and best practice business model as a strategy to reduce costs and to operate business activities more profitably and sustainably.

A limitation of this study is that although three different sources of data were used, that is company documentation, interviews and testimonials, it is inevitable that these sources of information were somewhat biased towards TSAM. The senior managers interviewed have vested interests in TSAM and as a result may present a biased view. In addition the company documentation is inward oriented and maybe biased towards TSAM.

It is recommended that future studies explore the application of the integrated lean, green best practice business model in other industries and in other countries. It is also recommended that comparative studies explore the application of the integrated business model in the automotive sector in different countries.

\section{Acknowledgements Competing interests}

The authors declare that they have no financial or personal relationships that may have inappropriately influenced them in writing this article.

\section{Authors' contributions}

A.W. (University of Johannesburg), R.L. (University of Johannesburg), G.J.H. (University of Johannesburg) and N.M.P. (University of Johannesburg) were equally responsible for the research and writing of this article.

\section{References}

Anderson, B., Bider, I., Johannesson, P. \& Perjons, E., 2005, 'Towards a formal definition of goal-oriented business process patterns', Business Process Management Journal 11(6), 650-662. http://dx.doi.org/10.1108/14637150510630846

Bergmiller, G.G. \& McCright, P.R., 2009, 'Parallel models for lean and green operations', in Proceedings of the 2009 Industrial Engineering Research Conference, University of South Florida and Zero Waste Operations Research and Consulting, viewed May 2011, from http://zworc.com/site/publications_assets/parallelmodels.pdf
Beske, P. \& Seuring, S., 2014, 'Putting sustainability into supply chain management', Supply Chain Management: An International Journal 19(3), 322-331. http:// dx.doi.org/10.1108/SCM-12-2013-0432

BMGI Corporation, 2009, 'Lean enterprise training material', Breakthrough Management Group 1(1), 3-59.

Business Blog, 2012, Understanding the concept of value, viewed April 2012, from http://www.abusinessblog.com/

Cabral, I., Grilo, A. \& Cruz-Machado, V., 2012, 'A decision-making model for lean, agile, resilient and green supply chain management', International Journal of Production Research 50(17), 4830-4845. http://dx.doi.org/10.1080/00207543.2012.657970

Castillo, G., Alarcón, L. \& González, V., 2015, 'Implementing lean production in copper mining development projects: Case study', Journal of Construction Engineering Management 141(1), 1-14. http://dx.doi.org/10.1061/(ASCE)CO.1943-7862.0000917

D'Amato, A., Henderson, S. \& Florence, S., 2009, Corporate social responsibility and sustainable business, Centre for Creative Leadership, Greensboro, NC.

De Brito, M.P. \& Dekker, R., 2003, A framework for reverse logistics. Erasmus University Rotterdam, Version April-2003, viewed June 2010, from http://repub.eur.nl/res/ pub/354/ERS-2003-045-LIS.pdf

Dornfeld, D.A., 2009, Opportunities and challenges to sustainable manufacturing and CMP, viewed May 2010, from http://impact.ee.ucla.edu/internal/document2/ Dornfeld-MRS-SP-2009.pdf

Dües, C.M., Tan, K.H. \& Lim, M., 2013, 'Green as the new lean: How to use lean practices as a catalyst to greening your supply chain', Journal of Cleaner Production 40, 93-100. http://dx.doi.org/10.1016/j.jclepro.2011.12.023

Engel, B., 2011, Ten best practices you should be doing now, viewed January 2012, from http://www.supplychainquarterly.com/topics/Procurement/ scq201101bestpractices/

EPA, 2003a, Lean manufacturing and the environment, office of solid waste and emergency responses, Contract EPA 100-R-03-005, US Environmental Protection Agency, USA.

EPA, 2003b, Lean manufacturing and the environment, research on advanced manufacturing systems and the environment and recommendations for leveraging better environmental performance, Contract EPA 100-R-03-005, US Environmental Petter environmental Agency, USA.
Protection

Evans, M.H., 2010, Organisational development: Defining best practice, viewed February 2011, from http://www.exinf.com

Franchetti, M., Bedal, K., Ulloa, J. \& Grodek, S., 2009, Lean and green: Industria engineering methods are natural stepping stones to green engineering, viewed March 2010, from http://www.highbeam.com

Galeazzo, A., Furlan, A. \& Vinelli, A., 2014, 'Lean management, supply chain management and sustainability: A literature review', Journal of Cleaner Production 85, 191-200.

Groznik, A. \& Maslaric, M., 2009, 'Achieving competitive supply chain through business process re-engineering: A case from developing country', African Journal of Business Management 4(2), 140-148.

Hackett Group, 2006, The Hackett Group warns of widening performance gap in the back offices of large global corporation, viewed January 2011, from http://www. thehackettgroup.com

Hammer, M., 1999, 'How process enterprises really work', Harvard Business Review, November-December, 108-118.

Hitachi Consulting Corporation, 2009, Six key trends changing supply chain management today: Choosing the optimal strategy for your business, viewed February 2013, from http://www.hitachiconsulting.com/files/pdfRepository/ WP_SCMTrends.pdf

Ho, J.C., Shalishali, M.K., Tseng, T. \& Ang, D.S., 2009, 'Opportunities in green supply chain management', The Coastal Business Journal 8(1), 18-31.

IBM, 2009, Optimize supply chains and operations, viewed July 2009, from http:// www-935.ibm.com

ISO Online, 2011, ISO 14000 essentials, viewed February 2011, from http://www.iso. org/iso/iso_14000_essentials

Jarrar, Y.F. \& Zairi, M., 2010, Best practice transfer for future competitiveness. Research paper: RP-ECBPM/0018, University of Bradford, viewed November 2010, from http://www.ecbpm.com

Jones, C., 1998, 'Moving beyond ERP: Making the missing link', Logistics Focus 6(7), 187-192.

Kotelnikov, V., 2001, Leadership vs. management, viewed February 2010, from http:// www.1000ventures.com/business_guide/crosscuttings/leadership_vs_mgmt.html

Lamming, R. \& Hampson, J., 1996, 'The environment as a supply chain issue', British Journal of Management 7, 45-62.

Liker, J.L., 2004, The Toyota Way: 14 Management principles from the world's greatest manufacturer, McGraw-Hill, New York, NY.

Mallett, T., 2010, Smoothing the road to green distribution practices, viewed May 2010, from http://supplychainonline.co.za/ArticleDetail.aspx?ID=1010

Martínez-Jurado, P.J. \& Moyano-Fuentes, J., 2014, 'Lean management, supply chain management and sustainability: A literature review', Journal of Cleaner Production 85, 134-150. http://dx.doi.org/10.1016/j.jclepro.2013.09.042

Meyer, D., 2009, Lean, green manufacturing intersects with sustainable supply chain management, creates value, viewed January 2011, from http://www. Valuestreem2009.com

Meyer, K.E., 2009, Corporate strategies under pressures of globalisation: Global focusing, viewed October 2012, from http://www.bath.ac.uk/management/ research/pdf/2009-03.pdf 
Ninlawan, C., Seksan, P., Tossapol, K. \& Pilada, W., 2010, 'The implementation of green supply chain management practices in electronics industry', Proceedings of the International Multi Conference of Engineers and Computer Scientists 3, Hong Kong.

OICA, 2013, World vehicle production reached 84.1 million in 2012, viewed July 2013, from http://www.autoalliance.org/index.cfm?objectid=B3FCE470-874311E2-BB6A000C296BA163

Olesen, P., Powell, D., Hvolby, H-H. \& Fraser, K., 2015, 'Using lean principles to drive operational improvements in intermodal container facilities: A conceptua framework', Journal of Facilities Management 13(3), 266-281. http://dx.doi. org/10.1108/JFM-09-2014-0030

Ponis, S.T. \& Koronis, E., 2012, 'Supply chain resilience: Definition of concept and its formative elements', The Journal of Applied Business Research 28(5), 921-929.

Ponis, S.T. \& Spanos, A.C., 2009, 'ERP II systems to support dynamic, reconfigurable and agile virtual enterprises', International Journal of Applied Systemic Studies 2(3), 265-283. http://dx.doi.org/10.1504/IJASS.2009.027664

Porter, M., 2001, Strategy and the Internet, viewed July 2012, from http://hbr org/2001/03/strategy-and-the-internet/ar/1

Rodrigue, J., Slack, B. \& Comtois, C., 2012, The geography of transport systems: Green logistics, viewed December 2012, from http://people.hofstra.edu/geotrans/eng/ ch8en/appl8en/ch8a4en.htm

Rothenberg, S., Pill, F.K. \& Maxwell, J., 2001, 'Lean, green and the quest for superio environmental performance', Production and Operations Management 10(3), 228-243. http://dx.doi.org/10.1111/j.1937-5956.2001.tb00372.x

Schaltegger, S. \& Burritt, R., 2014, 'Measuring and managing sustainability performance of supply chains: Review and sustainability supply chain management framework' Supply Chain Management: An International Journal 19(3), 232-241. http:// dx.doi.org/10.1108/SCM-02-2014-0061

Schmidt, J.G. \& Lyle, D., 2010, Lean integration: An integration factory approach to business agility, vol. 1, Addison-Wesley Professional, Boston, MA.

Siemens, 2008, Automotive: Answers for industry, viewed February 2012, from http:// www.siemens.com/automotive

Singh, S., Bharati, S. \& Kumar, M., 2013, 'Strategic framework for reverse logistics in pharmaceutical industry, Indian Institute of Information Technology, Asian Journal of Business Management 1(1), 11-28.

Sobral, M., Jabbour, A. \& Jabbour, C., 2013, Green benefits from adopting lean manufacturing, Wiley, New York, NY.

Srinivas, H., 2011, Sustainability concepts: Green procurement, viewed June 2011, from http://www.gdrc.org/sustdev/concepts
Sternbeck, M.G. \& Kuhn, H., 2014, 'Grocery retail operations and automotive logistics: A functional cross-industry comparison', Benchmarking: An International Journal 21(5), 814-834. http://dx.doi.org/10.1108/BIJ-07-2012-0048

Stindt, D. \& Sahamie, R., 2014, 'Review of research on closed loop supply chain management in the process industry', Flexible Services and Manufacturing Journal 26(1), 268-293. http://dx.doi.org/10.1007/s10696-012-9137-4

Toyota Blog Online, 2012, Toyota dominates 2012 Ipsos automotive quality awards, viewed February 2013, from http://toyotablog.co.za/blog-entry/toyota-dominates -2012-ipsos-automative-quality-awards

Toyota South Africa Motors (TSAM), 2012, Toyota South African Motors sustainability report 2012, TSAM, Pretoria.

Toyota South Africa Motors (TSAM), 2013, Toyota South African Motors sustainability report 2013, TSAM, Pretoria.

Vermaak, T.D., 2008, Critical success factors for the implementation of lean thinking in South African manufacturing organisations, University of Johannesburg, Gauteng.

Verrier, B., Rose, B. Caillaud, E. \& Remita, H. 2014 'Combining organizational performance with sustainable development issues: The lean and green project benchmarking repository', Journal of Cleaner Production 85, 83-93. http://dx.doi. org/10.1016/j.jclepro.2013.12.023

Wagner, E., Scott, S. \& Galliers, R.D., 2006, 'The creation of "best practice" software: Myth, reality and ethics', Information and Organization 16(3), 251-275. http:// dx.doi.org/10.1016/j.infoandorg.2006.04.001

Westlake, D., 2012, Cardboard packaging advantages, viewed august 2012, from http://www.ehow.com

Whitelaw, K., 2004, ISO 14001 Environmental Systems Handbook, vol. 2, Elsevier, Amsterdam.

Wills, B., 2009, The business case for environmental sustainability: Achieving rapid returns from the practical integration of lean \& green, rev. A02-09, HPS Inc. Paulsboro, NJ.

Womack, J.P. \& Jones, D.T., 2005, 'Lean consumption', Harvard Business Review 83(3), 58-68.

Wu, G., Cheng, Y. \& Huang, S., 2010, 'The study of knowledge transfer and green management performance in green supply chain management', African Journal of Business Management 4(1), 44-48.

Zokaei, K., Lovins, H., Wood, A. \& Hines, P., 2013, Creating a lean and green business system, Productivity Press, New York, NY. 